\title{
Biologic Implications from an Epidemiologic Study of Chromate Production Workers
}

\author{
Herman Gibb ${ }^{*, 1}$, Heather J. Hoffman ${ }^{2}$ and Cary Haver ${ }^{1}$ \\ ${ }^{I}$ Tetra Tech Sciences, Arlington, VA, USA \\ ${ }^{2}$ The George Washington University, Department of Epidemiology and Biostatistics, USA
}

\begin{abstract}
This analysis of an epidemiologic study of chromate production workers evaluates several variables related to the biologic understanding of chromate-induced lung cancer. Age at hire was found to be negatively associated with lung cancer risk. Reducing exposure was found to have benefits that extended into older age, and the benefits were greater when the reduction began at an earlier age. The same cumulative exposure over a short period of time (30 days) had more effect than if the exposure occurred over 10 years. The greater carcinogenic effect among those exposed at an early working age is consistent with an ability to more efficiently reduce hexavalent chromium intracellularly at younger ages. The greater effect at younger ages may also explain why short-term cumulative hexavalent chromium exposure was found to have more effect than the equivalent cumulative exposure spread over a longer term. The SMR for lung cancer was highest in the decade following cessation of exposure and may reflect the extremely irritating nature of hexavalent chromium.
\end{abstract}

Keywords: Hexavalent chromium, biologic, age, first exposure, peak, cumulative, chromate, workers, occupational, lung cancer, risk.

\section{INTRODUCTION}

Over a quarter of a century ago, at the $10^{\text {th }}$ Scientific Meeting of the International Epidemiological Association, Sir Richard Doll described the importance of epidemiological information in assessing occupational cancer [1]. In his presentation, Doll noted several factors that must demonstrate a "biologically sensible relationship" with the incidence of cancer if the exposure is to be regarded as a cause of the disease. Doll stated that the strongest positive evidence of an occupational hazard is the demonstration of a dose-response relationship between intensity of exposure and the subsequent incidence of disease. He noted, however, that the best that can often be done is a classification of exposure into broad categories such as low, medium and high. Given the frequent lack of actual exposure information, he declared that at least duration of exposure and time since exposure can always be measured precisely, but that few, if any, studies provide enough data to assess these components simultaneously. In his remarks, Doll also stated that he hoped that future occupational studies would examine how occupational hazards interact with non-occupational factors such as smoking and biological factors such as the age when first exposed.

Today, much as when Sir Richard made his presentation in 1984, detailed exposure information in occupational epidemiologic studies is the exception rather than the rule. Analysis of the interaction of suspected occupational hazards

*Address correspondence to this author at the Tetra Tech Sciences, 2200 Wilson Blvd., Suite 400, Arlington, VA 22201, USA; Tel: 571-5271701/703-684-0123; Fax: 703-684-2223;

E-mail: Herman.Gibb@tetratech.com with non-occupational factors, as Sir Richard had hoped for, is generally not undertaken because of lack of information. The issues which Sir Richard described are highly relevant to the topic of this special journal issue. The present analysis will examine some of these issues utilizing an epidemiologic study for which detailed exposure information and data on smoking are available.

\section{METHODS}

The study used for this analysis is a cohort study of 2357 chromate production workers first employed between August 1, 1950 and December 31, 1974 [2]. Cumulative hexavalent chromium exposure ( $\mathrm{Cr} 6)$ (measured in $\mathrm{mg} \mathrm{Cr}_{3} / \mathrm{m}^{3}$-years) for each member of the cohort was based on job history and annual average exposure estimates of hexavalent chromium. Average annual airborne hexavalent chromium concentrations for each job title were based on approximately 70,000 contemporary measurements spanning the period from 1950 through 1985, the year the plant closed. The hexavalent chromium measurements taken by the facility described in Gibb et al. [2] were intended to capture "typical/usual exposures." Thus episodic occurrences are not reflected in the average annual airborne hexavalent chromium concentrations.

Airborne trivalent chromium concentrations were estimated through the use of measured hexavalent chromium concentrations and the ratio of hexavalent to trivalent chromium concentration in settled dust in the facility. Smoking information (yes/no) as of the beginning of employment was available for over $91 \%$ of the cohort. Clinical signs of potential chromium irritation were identified from company records [3]. Follow-up of the cohort was through December 31, 1992. There were 122 cases of lung cancer and approximately 71,000 person-years of observation. 
There was a clear lung cancer exposure response by $\mathrm{Cr} 6$ quartile [2]. A proportional hazards model of $\log _{10} \mathrm{Cr} 6, \log _{10}$ trivalent chromium, and smoking found that smoking and $\log _{10}$ Cr6, but not $\log _{10}$ trivalent chromium, were significantly associated with an increased risk of lung cancer ( $\mathrm{p}<0.05)$. A second proportional hazards model of $\log \mathrm{Cr} 6$, work duration, and smoking found that smoking and log Cr6, but not work duration, were significantly associated with an increased risk of lung cancer $(p<0.05)$. Workers experienced a wide variety of nasal and skin irritations [3].

In the current analysis, four bivariable analyses using Cox proportional hazards regression models were used to assess the risk of lung cancer from Cr6, cigarette smoking, age at hire, and work duration. A multivariable model was then fit to the data that included all variables considered significant at the 0.10 level of significance in the bivariable analyses and all possible two-way interactions. Although no interaction between smoking and the $\log _{10} \mathrm{Cr} 6$ was found in Gibb et al. [2], it was decided to include the $\mathrm{Cr} 6 *$ smoking interaction in this model for several reasons. One reason was that $\mathrm{Cr} 6$, not the $\log _{10} \mathrm{Cr} 6$ used in Gibb et al. [2], was used as the exposure metric. Secondly, the interaction is biologically plausible. Third, the model included multiple terms not considered by Gibb et al. [2]. All possible nested models were compared. The likelihood ratio test and Akaike's Information Criterion were used to select the multivariable model that best explained the data with a minimum of free parameters.

Using the best model, relative risks (RRs) and their corresponding $95 \%$ confidence intervals were calculated to compare (1) differing levels of $\mathrm{Cr} 6$ exposure, (2) smokers to nonsmokers, (3) differing ages at hire, and (4) differing work durations. For the remaining interaction terms variables were controlled by setting them equal to their median values. All statistical analyses were performed using $\mathrm{SAS}^{\circledR}$ Release 9.1 .

In order to make internal comparisons, a $\mathrm{Cr} 6$ exposure of $0.000001 \mathrm{mg} / \mathrm{m}^{3}$ was arbitrarily used as the baseline risk to represent no occupational exposure.

Standardized mortality ratios (SMRs) for lung cancer for each Cr6 quartile and by time since termination of exposure were developed using the NIOSH Life Table Analysis System (LTAS). The LTAS program adjusts for calendar year, age, and gender and uses US mortality rates for 119 causes of death for the period 1940 to 2002 as the reference population. SMRs are based on 122 lung cancer deaths and 70,716 person years of observation.

\section{RESULTS}

Descriptive statistics for the cohort are presented in Table 1. Table $\mathbf{1}$ is adapted from Table II of Gibb et al. [2] but also includes time from termination of work to the date of death or end of follow-up. Eighty-two percent $(n=1,753)$ of the study cohort smoked cigarettes. Among the lung cancer cases, there were 4 nonsmokers.

Results of the bivariable Cox proportional hazards regression models predicting lung cancer risk are reported in Table 2. Hazard ratios correspond to a one unit increase in the independent variable $\left(1 \mathrm{mg} / \mathrm{m}^{3}\right.$-years $\mathrm{Cr} 6$, one year age at

Table 1. Description of Cohort by Cumulative Hexavalent Chromium Exposure, Years of Work, Age at Hire, Years of Follow-Up, Time Since Last Exposure, and Calendar Year of Hire

\begin{tabular}{|c|c|c|c|c|c|c|c|}
\hline & & $\begin{array}{c}\mathrm{Cr6} \\
\left(\mathrm{mg} / \mathrm{m}^{3}-\text {-Years }\right)\end{array}$ & $\begin{array}{l}\text { Work } \\
\text { Years }\end{array}$ & $\begin{array}{c}\text { Years of } \\
\text { Follow-Up }\end{array}$ & $\begin{array}{l}\text { Age at } \\
\text { Hire }\end{array}$ & $\begin{array}{c}\text { Time Since } \\
\text { Last Exposure }\end{array}$ & $\begin{array}{c}\text { Calendar Year } \\
\text { of Hire }\end{array}$ \\
\hline \multirow{3}{*}{ Mean } & total group & 0.134 & 3.1 & 30 & 30.2 & 26.9 & 1957 \\
\hline & lung ca cases & 0.291 & 5.3 & 27.9 & 33.3 & 22.5 & 1953 \\
\hline & non-cases & 0.126 & 3 & 30.1 & 30 & 27.2 & 1958 \\
\hline \multirow{2}{*}{$\begin{array}{l}\text { Standard } \\
\text { Deviation }\end{array}$} & total group & 0.357 & 6.5 & 9.6 & 7.5 & 11.6 & 7.7 \\
\hline & non-cases & 0.336 & 6.3 & 9.7 & 7.4 & 11.6 & 7.8 \\
\hline \multirow{3}{*}{ Median } & total group & 0.009 & 0.39 & 31.2 & 28.6 & 28.0 & 1954 \\
\hline & lung ca cases & 0.016 & 0.84 & 28.9 & 31.6 & 24.1 & 1953 \\
\hline & non-cases & 0.009 & 0.41 & 31.1 & 28.5 & 28.3 & 1954 \\
\hline Min/Max & non-cases & $0.0 / 5.259$ & $0.003 / 37.9$ & $0.3 / 42.4$ & $16.9 / 62.9$ & $0 / 42.4$ & $1950 / 1974$ \\
\hline \multirow{3}{*}{$\begin{array}{c}\text { 25th } \\
\text { Percentile }\end{array}$} & total group & 0.001 & 0.088 & 22.6 & 24.3 & 19.1 & 1951 \\
\hline & lung ca cases & 0.002 & 0.167 & 22.1 & 26.3 & 14.8 & 1951 \\
\hline & non-cases & 0.001 & 0.085 & 22.7 & 24.3 & 19.4 & 1951 \\
\hline \multirow{3}{*}{$\begin{array}{c}\text { 75th } \\
\text { Percentile }\end{array}$} & total group & 0.076 & 2 & 38.9 & 34.4 & 37.2 & 1965 \\
\hline & lung ca cases & 0.234 & 4.6 & 35.1 & 39.2 & 32.4 & 1954 \\
\hline & non-cases & 0.076 & 2 & 39.2 & 34.2 & 37.4 & 1965 \\
\hline
\end{tabular}


hire, one year work duration, smokers $v s$ nonsmokers). Age at hire demonstrated a negative association with lung cancer risk indicating that a younger age at hire incurred more lung cancer risk.

Table 2. Bivariable Analyses for Cumulative Hexavalent Chromium Exposure, Age at Hire, Work Duration, and Smoking Using Cox Proportional Hazards Regression Models

\begin{tabular}{|c|c|c|c|c|}
\hline & $\begin{array}{c}\text { Parameter } \\
\text { Estimate }\end{array}$ & p-Value & $\begin{array}{c}\text { Hazard } \\
\text { Ratio }\end{array}$ & $\begin{array}{c}\text { Hazard Ratio } \\
\mathbf{9 5 \%} \text { CI }\end{array}$ \\
\hline \hline Cr6 & 0.48 & $<0.0001$ & 1.62 & $1.29-2.04$ \\
\hline Age at Hire & -0.03 & 0.063 & 0.98 & $0.95-1.00$ \\
\hline Work Duration & 0.04 & 0.0003 & 1.04 & $1.02-1.06$ \\
\hline Smoking & 1.78 & 0.0005 & 5.92 & $2.18-16.04$ \\
\hline
\end{tabular}

All four variables in the bivariable analyses were considered to have an effect on lung cancer; thus the multivariable model was fit with all four variables and all possible two-way interactions. Using the likelihood ratio test, we concluded that the best fitting reduced (nested) model included Cr6, smoking status, age at hire, work duration, and the three two-way interactions between Cr6 and (1) smoking status, (2) age at hire, and (3) work duration, $(\mathrm{p} \leq 0.0001)$. This model also yielded the smallest (best) AIC value confirming its superior goodness of fit compared to the other nested models. Results are summarized in Table 3. Cr6* smoking status interaction $(\mathrm{p}=$ $0.0548)$, and $\mathrm{Cr}^{*}$ work duration interactions $(\mathrm{p}=0.0584)$ were marginally significant in the model at the 0.05 level but contributed to the overall model fit.

Based on the model the RRs of lung cancer for those hired at ages 30, 40, and 50, compared to those hired at age 20 , are $0.87,0.75$, and 0.65 , respectively. Relative risks increased with increasing work duration. Compared to working for 30 days, the RRs of working for 6 months, 1 year, 5 years, and 10 years are 1.02 (95\% CI 1.00, 1.03), 1.03 (95\% CI 1.00, 1.06) 1.19 (95\% CI 1.00, 1.40), and 1.41 (95\% CI 1.01, 1.97), respectively.

Table $\mathbf{4}$ is a comparison of relative risks for the median of the highest quartile of exposure at different work durations, relative to the baseline risk (no exposure). For 30 days work duration, the relative risk is 1.41 (95\% CI 1.07, $1.85)$ and $1.82(95 \%$ CI $1.21,2.74)$ for smokers and nonsmokers, respectively. For a work duration of 10 years, the relative risk decreases to $1.24(95 \% \mathrm{CI} 0.68,2.27)$ and 1.61
(95\% CI 0.87, 2.98) for smokers and non-smokers, respectively. In other words, a high cumulative exposure over a short period of time presented more risk than the same cumulative exposure spread over a much longer duration. Notice also that for each duration of work examined, the relative risk is greater for non smokers than for smokers.

Table 3. Multivariable Cox Model for Cumulative Hexavalent Chromium Exposure, Smoking, Age at Hire, Work Duration, and Associated Interaction Terms

\begin{tabular}{|c|c|c|c|c|}
\hline & $\begin{array}{c}\text { Parameter } \\
\text { Estimate }\end{array}$ & p-Value & $\begin{array}{c}\text { Hazard } \\
\text { Ratio }\end{array}$ & $\begin{array}{c}\text { Hazard Ratio } \\
\text { 95\% CI }\end{array}$ \\
\hline \hline Cr6 & 3.25 & 0.0008 & 25.90 & $3.86-173.75$ \\
\hline Smoking & 2.31 & 0.0006 & 10.04 & $2.71-37.15$ \\
\hline Age at Hire & -0.01 & 0.316 & 0.99 & $0.96-1.01$ \\
\hline Work Duration & 0.04 & 0.0438 & 1.04 & $1.00-1.07$ \\
\hline Cr6* Smoking & -0.77 & 0.0548 & 0.47 & $0.21-1.02$ \\
\hline Cr6*Age at Hire & -0.05 & 0.0361 & 0.95 & $0.91-1.0$ \\
\hline Cr6*Work Duration & -0.04 & 0.0584 & 0.96 & $0.93-1.00$ \\
\hline
\end{tabular}

To examine the benefit of reducing exposure, the difference in the cumulative hazard rate for exposures of $0.34 \mathrm{mg} / \mathrm{m}^{3}$-years, the median of the highest exposure quartile, and $0.00045 \mathrm{mg} / \mathrm{m}^{3}$-years, the median of the lowest quartile, were examined for different time periods following termination of exposures. Fig. (1) examines this difference for smokers who worked one year and started work at ages 20 or 40 . The benefit of exposure reduction increases with time since last exposure regardless of age at hire. The benefit becomes apparent less than 20 years after termination of exposure. Around 40 years following termination of exposure, the decrease in risk is almost the same whether the age at hire is 20 or 40 years old. In other words, decreasing the exposure for one beginning exposure at an early age has more effect than decreasing the exposure when exposure begins at a later age.

In addition to the model described, standardized mortality ratios (SMRs) were calculated to evaluate risks in relation to an external population. The SMRs compare the lung cancer mortality rate among the cohort members to that occurring in the U.S. adjusted for age, race, sex, and calendar year. The lung cancer SMR for the entire cohort was 1.81 (95\% CI 1.51, 2.16). The SMR analysis demonstrates a clear dose response for cumulative exposure (Fig. 2). For all but the first quartile of exposure (0 to $0.001 \mathrm{mg} / \mathrm{m}^{3}$-years $\mathrm{Cr} 6$ ),

Table 4. Relative risks (95\% Confidence Intervals) of Lung Cancer Mortality for Exposure to $0.339 \mathrm{mg} / \mathrm{m}^{3}$-Years of Cumulative Hexavalent Chromium (the Median of the $4^{\text {th }}$ Quartile of Exposure) for Smokers and Nonsmokers for Different Work Durations Adjusted by Age at Hire, Work Duration, and Associated Cr6 Interaction Terms

\begin{tabular}{|c|c|c|c|c|c|}
\hline & 30 Days & 6 Months & 1 Year & 5 Years & 10 Years \\
\hline \hline Smokers & 1.41 & 1.40 & 1.39 & 1.32 \\
& $(1.07-1.85)$ & $(1.05-1.85)$ & $(1.03-1.86)$ & $(0.87-2.27)$ & $(0.68-2.27)$ \\
\hline Non-Smokers & 1.82 & 1.81 & 1.80 & 1.71 \\
$(1.21-2.74)$ & $(1.21-2.72)$ & $(1.20-2.71)$ & 1.61 \\
& $(1.06-2.75)$ & $(0.87-2.98)$ \\
\hline
\end{tabular}


significantly more deaths occurred than would be expected based on U.S. mortality rates.

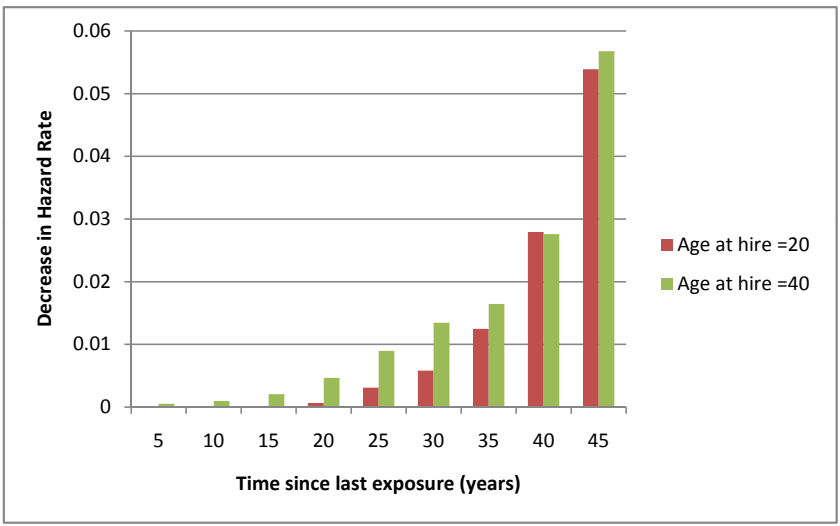

Fig. (1). Hazard rate decrease caused by decreasing Cr6 from 0.34 to $0.00045 \mathrm{mg} / \mathrm{m}^{3}$-years among smokers who worked for 1 year by age at hire, accounting for age at hire, work duration, and Cr6 interaction terms.

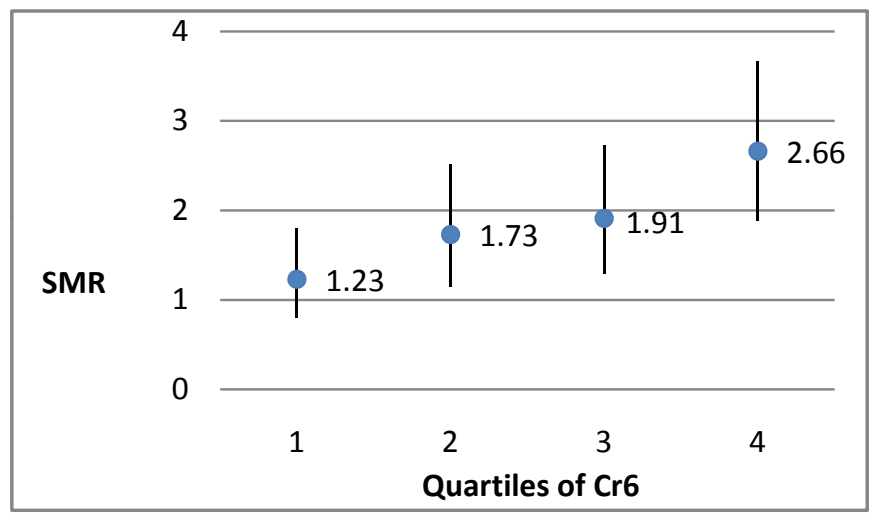

Fig. (2). SMRs and 95\% confidence intervals (adjusted for age, sex, race, and calendar year) by quartiles of cumulative hexavalent chromium exposure.

The lung cancer SMRs by time since last exposure for the cohort are described in Fig. (3). The SMR is highest in the first 10 years following last exposure. While SMRs decrease with time since the last exposure, $95 \%$ confidence intervals do not reach one even after 30 years since termination of employment.

\section{DISCUSSION}

This analysis examined the effect on lung cancer risk of work duration, age at hire, smoking, and Cr6 in a group of chromate production workers. Cr6, smoking, and duration of exposure were found to be clearly related to lung cancer risk in a multivariable regression which also included age at hire and several interaction terms.

Age at hire was not significantly associated with lung cancer risk in the multivariable regression, but the interaction term, age at hire*Cr6, was significantly correlated (Table $\mathbf{3}$ ). The model clearly demonstrated a stronger effect when Cr6 exposure begins at an early age. Enterline [4], in an analysis of early studies of chromate workers, also reported that those exposed at younger ages had a higher risk of lung cancer. It has been hypothesized that the carcinogenic mechanism of action of hexavalent chromium is the intracellular reduction of hexavalent to trivalent chromium and the concomitant generation of reactive intermediates $[5,6]$. The reduction of hexavalent chromium is accomplished at least in part by glutathione [5-8]. An age-related reduction in glutathione has been reported in laboratory animals and mussels [9-11]. An age-related reduction in gluatathione in humans could thus explain, at least to some degree, the higher risk when exposure begins at an earlier age.

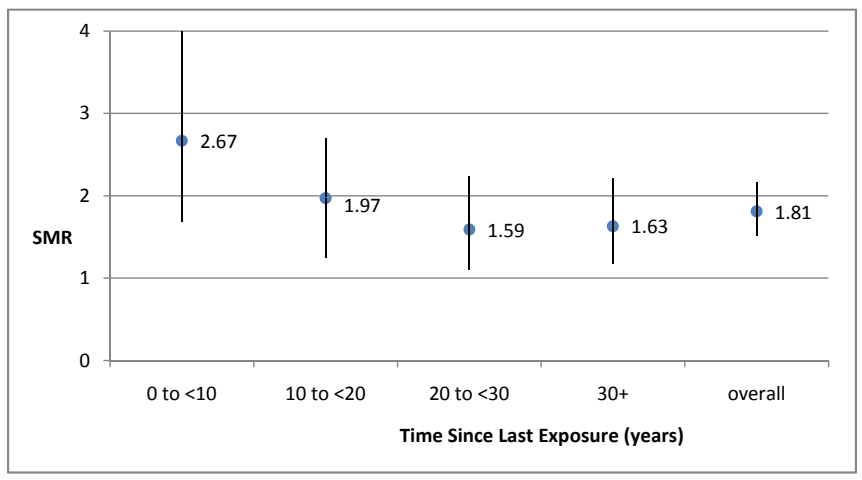

Fig. (3). Lung cancer SMRs and 95\% confidence intervals (adjusted for age, sex, race, and calendar year) stratified by time since last exposure.

Duration of exposure is positively demonstrated with increased probability of dying from lung cancer as demonstrated by Table 3. The interaction term of $\mathrm{Cr} 6 *$ work duration was negatively correlated with lung cancer risk ( $\mathrm{p}=$ 0.0584) (Table 3) suggesting that higher exposure over a shorter period has more effect than the same cumulative exposure spread over a longer period of time. This was demonstrated in a comparison of relative risks for the same cumulative exposure for time periods ranging from 30 days to 10 years (Table $\mathbf{4}$ ).

The negative correlation for the interaction term $\mathrm{Cr} 6 * \mathrm{Cig}$ Smoke is somewhat puzzling (Table 3), but there were only four lung cancer cases in the cohort who did not smoke. Thus conclusions regarding interaction are problematic. It was interesting to note, however, that the relative risks for nonsmokers were higher than those for smokers for the same cumulative exposure for different work durations (Table 4). That is consistent with the negative interaction that was observed for smoking and Cr6. Still, whether the negative interaction has any significance is questionable given the small number of lung cancer cases who did not smoke. Similar to Gibb et al. [2], the Cr6*smoking interaction was not statistically significant $(\mathrm{p}<0.05)$.

Similar to the results of Gibb et al. [2] the SMRs for lung cancer increased by exposure quartile (Fig. 2). The SMRs by quartile in the current analysis are slightly different than those in Gibb et al. [2]. Gibb et al. [2] used the state of Maryland as the reference population and exposures were lagged five years. The current analysis uses U.S. population, and the exposures are not lagged.

As one would expect if $\mathrm{Cr} 6$ was increasing the risk of lung cancer, the lung cancer SMR for the cohort increased 
following the end of exposure. Of interest is the pattern of the SMRs over time after exposure ended. The highest lung cancer SMR in the cohort occurred < 10 years after exposure ended. The SMR decreased in subsequent decades and then rose slightly (Fig. 3). Enterline [4] also found that the lung cancer risk in a cohort of chromate production workers was highest shortly after the cohort was identified. The author commented that the short latent period was probably the result of exposure to "a very potent carcinogen." The carcinogenic mechanism of hexavalent chromium and its description as a "very potent carcinogen" may well relate to its extremely irritating nature. The role of irritation in tumor development (Virchow's Theory) has been reported with respect to other substances and device [12-15]. Over $60 \%$ of the Gibb et al. [3] cohort experienced irritated and ulcerated nasal septa that occurred in less than 3 months. The irritating nature of hexavalent chromium is also reflected by work duration. The median duration of work for the cohort was less than 5 months. The $75^{\text {th }}$ percentile was only two years.

The current analysis found that the same cumulative exposure over a short period of time (30 days) had more effect than if exposure occurred over 10 years. Samet et al. [16] noted the concerns of using pack-years, a measure of cumulative exposure, as the exposure metric for cigarette smoking and lung cancer risk. Other authors have also noted the limitations of cumulative exposure as an exposure metric. Beane Freeman et al. [17] found that the risk of lymphohematopoietic tumors was associated with peak exposure to formaldehyde but not with cumulative or average exposure. Sielken et al. [18] reported that the prediction of leukemia risk from cumulative butadiene exposure was significantly improved when age and peak exposure were included in the risk assessment model. Charbotel et al. [19] found an effect of trichloroethylene peak exposure on renal cell carcinoma.

Halmes et al. [20] compared short term to lifetime exposure for eleven carcinogenic compounds evaluated by the National Toxicology Program. The authors found that for most of the compounds which they evaluated, the carcinogenic risk from short term exposures was greater than the equivalent dose over a longer term exposure. The authors theorized that if a carcinogen affects a human or animal primarily in a particular life stage, a short term exposure during that stage may be very effective in producing cancer, while the same exposure during a different life stage may be ineffective. The current analysis suggests that hexavalent chromium exposure has a greater effect at age 20 than at age 40.

Future investigations using this cohort should examine in more detail the risk from short term exposures. The use of a counting process or other alternative approaches such as those employed by Chen and Gibb [21] and Chen [22] would help to address this issue. These alternative methodologies could also be used to further examine the issues of cessation lag and lingering effect. Assessment of time since last exposure is limited since the plant closed in 1985 and follow-up ended 7 years later in 1992. Additional follow-up and analysis of this cohort should provide interesting insight to the pattern of risk.

\section{CONCLUSION}

Lung cancer risk demonstrates a strong dose response relationship with hexavalent chromium. The relationship is influenced by the age at first exposure, the duration of exposure, and the period of time over which cumulative exposure occurs. The higher risk experienced by those employed at younger ages may reflect their ability to more efficiently reduce hexavalent chromium to trivalent chromium. This ability may also explain the greater effect of short term cumulative exposure compared to the same cumulative exposure spread over a longer term. The highest relative risk appears to occur shortly after the end of exposure, possibly reflecting the extremely irritating nature of hexavalent chromium. The benefits of reducing exposure appear to increase with time since cessation of exposure; the benefits appear to be greater when reduction of exposure begins at an earlier age, again reflecting the ability to more efficiently reduce hexavalent to trivalent chromium at younger ages.

\section{POTENTIAL CONFLICTS OF INTEREST}

Dr. Gibb has agreed to serve as an expert witness for a case in which plaintiffs were exposed to sodium dichromate. The other authors report no conflict of interest.

\section{ACKNOWLEDGEMENTS}

The authors thank Drs. Chao Chen and Arthur Chiu of the U.S. Environmental Protection Agency for their constructive comments.

\section{REFERENCES}

[1] Doll R. Occupational cancer: a hazard for epidemiologists. Int J Epidemiol 1985; 14: 22-31.

[2] Gibb HJ, Lees PS, Pinsky PF, Rooney BC. Lung cancer among workers in chromium chemical production. Am J Ind Med 2000; 38: 115-26.

[3] Gibb HJ, Lees PS, Pinsky PF, Rooney BC. Clinical findings of irritation among chromium chemical production workers. Am J Ind Med 2000; 38: 127-31.

[4] Enterline PE. Respiratory cancer among chromate workers. J Occup Med 1974; 16(8): 523-6.

[5] Shi X, Chiu A, Chen CT, Halliwell B, Castranova V, Vallyathan V. Reduction of chromium(VI) and its relationship to carcinogenesis. J Toxicol Environ Health B Crit Rev 1999; 2: 87-104.

[6] Shi X, Ding M, Ye J, et al. Cr(IV) causes activation of nuclear transcription factor-kappa B, DNA strand breaks and dG hydroxylation via free radical reactions. J Inorg Biochem 1999; 75: 37-44.

[7] Chiu A, Katz AJ, Beaubier J, Chiu N, Shi X. Genetic and cellular mechanisms in chromium and nickel carcinogenesis considering epidemiologic findings. Mol Cell Biochem 2004; 255: 181-94.

[8] Katz AJ, Chiu A, Beaubier J, Shi X. Combining Drosophila melanogaster somatic-mutation-recombination and electron-spinresonance-spectroscopy data to interpret epidemiologic observations on chromium carcinogenicity. Mol Cell Biochem 2001; 222: 61-8.

[9] Suh JH, Wang H, Liu RM, Liu J, Hagen TM. (R)-alpha-lipoic acid reverses the age-related loss in GSH redox status in post-mitotic tissues: evidence for increased cysteine requirement for GSH synthesis. Arch Biochem Biophys 2004; 423: 126-35.

[10] de la Asuncion JG, Millan A, Pla R, et al. Mitochondrial glutathione oxidation correlates with age-associated oxidative damage to mitochondrial DNA. FASEB J 1996; 10: 333-8.

[11] Viarengo A, Pertica M, Canesi L, Accomando R, Manicinelli G, Orunesu M. Lipid peroxidation and level of antioxidant compounds (GSH, Vitamin E)in the digestive glands of mussels of three different age groups exposed to anerobic and aerobic conditions. Mar Environ Res 1989; 28: 291-5. 
[12] Bainbridge WS. The Cancer Problem. New York: The Macmillion Company 1914.

[13] Cohen SM, Arnold LL, Cano M, Ito M, Garland EM, Shaw RA. Calcium phosphate-containing precipitate and the carcinogenicity of sodium salts in rats. Carcinogenesis 2000; 21: 783-92.

[14] Duhayon S, Hoet P, Van Maele-Fabry G, Lison D. Carcinogenic potential of formaldehyde in occupational settings: a critical assessment and possible impact on occupational exposure levels. Int Arch Occup Environ Health 2008; 81: 695-710.

[15] Vaccarezza GF, Antunes JL, Michaluart-Junior P. Recurrent sores by ill-fitting dentures and intra-oral squamous cell carcinoma in smokers. J Public Health Dent 2010; 70: 52-7.

[16] Samet JM, Thun MJ, de Gonzalez AB. Models of smoking and lung cancer risk: a means to an end. Epidemiology 2007; 18: 64951 .

[17] Beane Freeman LE, Blair A, Lubin JH, et al. Mortality from lymphohematopoietic malignancies among workers in formaldehyde industries: the National Cancer Institute Cohort. J Natl Cancer Inst. 2009; 101: 751-61.

[18] Sielken RL Jr, Valdez-Flores C, Gargas ML, Kirman CR, Teta MJ, Delzell E. Cancer risk assessment for 1,3-butadiene: dose-response modeling from an epidemiological perspective. Chem Biol Interact 2007; 166: 140-9.

[19] Charbotel B, Fevotte J, Hours M, Martin JL, Bergeret A. Casecontrol study on renal cell cancer and occupational exposure to trichloroethylene. Part II: Epidemiological aspects. Ann Occup Hyg 2006; 50: 777-87.

[20] Halmes NC, Roberts SM, Tolson JK, Portier CJ. Reevaluating cancer risk estimates for short-term exposure scenarios. Toxicol Sci 2000; 58: 32-42.

[21] Chen CW, Gibb H. Procedures for calculating cessation lag. Regul Toxicol Pharmacol 2003; 38(2): 157-65.

[22] Chen CW. Lingering effect: epidemiological information useful for risk assessment. Regul Toxicol Pharmacol 2008; 52: 242-7.

(C) Gibb et al.; Licensee Bentham Open.

This is an open access article licensed under the terms of the Creative Commons Attribution Non-Commercial License (http://creativecommons.org/licenses/by$\mathrm{nc} / 3.0 /$ ) which permits unrestricted, non-commercial use, distribution and reproduction in any medium, provided the work is properly cited. 